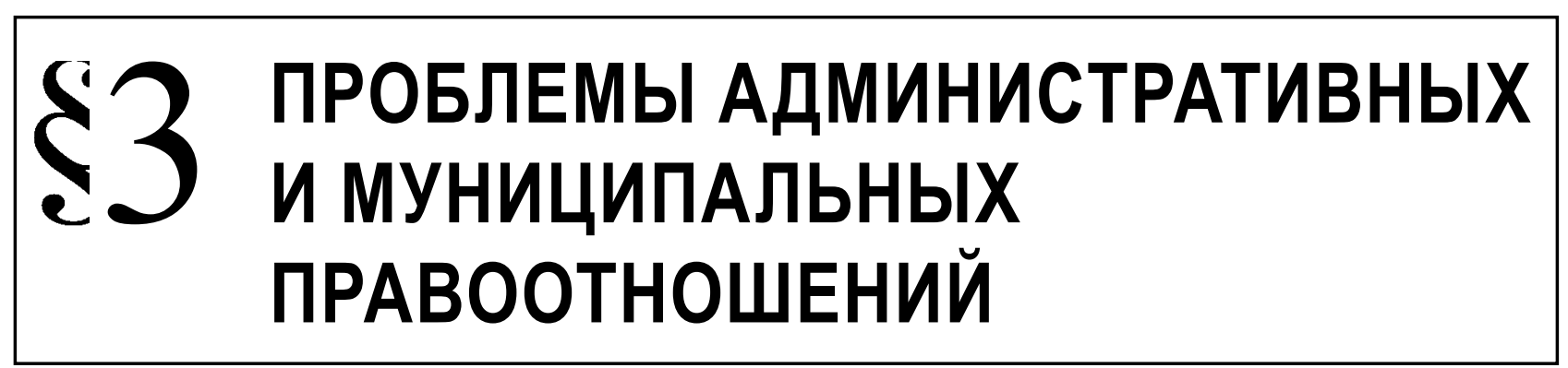

Николаенко Е.А.

\title{
К ВОПРОСУ О ПРОХОЖДЕНИИ КУРСАНТАМИ СЛУЖБЫ В ОРГАНАХ ВНУТРЕННИХ ДЕЛ
}

Аннотация. Предметом проведенного исследования является институт прохождения службы в органах внутренних дел, научная литература и действующее законодательство, позволяющие определить отличительные особенности прохождения службы в органах внутренних дел у основного контингента образовательных организаций высшего образования МВД России - курсантов. Объектом исследования являются общественные правоотношения, складывающиеся при поступлении граждан на обучение в образовательные организации высшего образования МВД России, при прохождении и прекращении ими службы в органах внутренних дел. Методологическую основу исследования составил комплекс общенаучных и специальных методов познания: системный, логический, сравнительно-правовой, метод перехода от абстрактного к конкретному, от общего к частному. Автор рассматривает условия и порядок поступления граждан на обучение, особенности присвоения специальных званий и проведения аттестации в отношении курсантов, особенности прекращения обучения и службы в органах внутренних дел курсантами. Автором доказана взаимосвязь и влияние двух сфер деятельности служебной и образовательной на служебно-правовое положение курсантов, выявлены проблемные вопросы, имеющиеся в правоприменительной практике прохождения курсантами службы в органах внутренних дел, и предложены пути решения.В заключение автор делает вывод, что такая представительная и значимая часть активных субъектов образовательных отношений и отношений, связанных с прохождением службы в органах внутренних дел, как курсанты не должна оставаться вне сферы государственного внимания.

Ключевые слова: служба, государственная служба, прохождение службы, орган внутренних дел, обучающийся, кадровый корпус, прекращение службы, служебно-правовое положение, образовательные отношения, аттестация.

Abstract. The research subject is the institution of cadetship in internal affairs agencies, scientific literature and the current legislation which help define the distinctive features of cadetship in higher education institutions of the Ministry of Internal Affairs of the Russian Federation. The research object is the range of social relations starting at the moment of a person's entry an educational institution of the Ministry of Internal Affairs, during the cadetship and at the moment of its termination. The research methodology is based on the set of general scientific and specific methods of cognition: the system and comparative-legal methods, the method of moving from abstract to concrete and from general to specific. The author considers the conditions and the order of entry into cadetship, the peculiarities of appointment to special grades and assessment, the peculiarities of study and service termination. The author proves the interrelation between and the influence of two spheres of activity - service and education - on the legal position of cadets; reveals the problem aspects of law enforcement practice of cadetship in internal affairs agencies and offers solutions to these problems. The author concludes that such a meaningful and significant part of active subjects of educational relations and service as cadets shouldn't lack the government's attention.

Key words: public service, cadetship, internal affairs agency, student, personnel, service termination, legal position, educational relations, assessment, service.

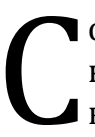
овременный подход к созданию профессионального кадрового корпуса полицейского ведомства, а также качественное комплектование его людьми, которые в максимальной степени соответствуют высоким требованиям статуса сотрудника органов внутренних дел, неразрывно связан с соответствующим организационным, социальным и материальным обеспечением прохождения сотрудниками службы в органах внутренних дел. 
Федеральный закон «0 системе государственной службы Российской Федерации», определяя в Российской Федерации организационные и правовые основы всей системы государственной службы в целом, а также систему управления государственной службой, в том числе устанавливает базовые элементы прохождения государственной службы [1].

В свою очередь Федеральные законы о соответствующем виде государственной службы, а также другие нормативные правовые акты детально определяют специфику соответствующего вида государственной службы, порядок поступления на службу соответствующего вида, порядок замещения вакантных должностей, формы и способы подготовки граждан для государственной службы соответствующего вида, порядок прохождения службы соответствующего вида, основания прекращения государственной службы соответствующего вида и так далее.

С 2011 года законодательство о службе в органах внутренних дел претерпело существенные изменения, и начался новый этап его развития и становления. С этого периода служба в органах внутренних дел, являясь разновидностью государственной службы, стала регламентироваться на федеральном уровне. Правоотношения, связанные с поступлением на службу в органы внутренних дел, ее прохождением, а также прекращением стали регулироваться Федеральным законом «О службе в органах внутренних дел Российской Федерации и внесении изменений в отдельные законодательные акты Российской Федерации» (далее Закон о службе) [2]. Закон о службе определил ключевые понятия, используемые в системе органов внутренних дел, а именно: «служба в органах внутренних дел», «должности в органах внутренних дел», «сотрудник органов внутренних дел», вместе с тем содержание понятия «прохождение службы в органах внутренних дел» до настоящего не имеет законодательного закрепления.

Горин В.Н. предлагает рассматривать прохождение службы в органах внутренних дел в виде совокупности служебно-функциональных и внутриорганизационных отношений, которые носят только административный характер, и это в очередной раз подчеркивает особенность правового положения сотрудника ОВД [3].

Многие ученые неоднократно исследовали содержание, и сущность данного понятия и с моей точки зрения наиболее полно определение «прохождение службы в ОВД» представлено в виде комплекса взаимосвязанных, связно выстроенных и законодательно урегулированных действий, которые непосредственно связаны с отбором, воспитанием, расстановкой, служебными перемещениями и ротацией сотрудников, обеспечением должност- ного роста и профессионального развития, оценкой служебной деятельности. При этом это не просто перечень методов, средств, принципов, форм и приемов для решения имеющихся кадровых вопросов, а целая система организационно-управленческой деятельности структурного, содержательного и функционального характера, которая сориентирована на достижение стратегических целей в управлении персоналом и качественном решении оперативно-тактических задач.

Прохождение службы в органах внутренних дел можно охарактеризовать следующими чертами:

1. Прохождение службы это длящийся процесс, который берет свое начало с момента становления государственно-служебных отношений и длится до момента прекращения данных отношений.

2. Прохождение службы имеет свое содержание, на протяжении которого реализуется правовой статус сотрудника.

3. Прохождение службы регулируется законодательно.

4. Прохождение службы осуществляется в соответствующих условиях (режим служебного времени, отпуска, денежное довольствие, гарантии и компенсации; государственное социальное страхование, обеспечение жилой служебной площадью, и т. д.)

5. Порядок прохождения службы в органах определяется специальным законодательством и ведомственными нормативными правовыми актами.

6. В органах внутренних дел прохождение службы происходит на различных должностях. Конкретная должность имеет свой специальный статус, который и предполагает наличие существенных обязательных требований к кандидату для ее замещения. После замещения должности кандидат приобретает статус сотрудника органа внутренних дел, который выполняет служебные обязанности и имеет права в пределах своей компетентности в соответствии с замещаемой должностью и действующим законодательством, заключенным контрактом и принимаемой Присягой.

Среди всех субъектов государственной службы в органах внутренних дел курсанты образовательных организаций высшего образования МВД России (далее - курсанты) занимают особое место и имеют свои отличительные особенности как служебно-правового положения, так и прохождения службы в органах внутренних дел. На административно-правовой статус курсантов в период прохождения ими службы в органах внутренних дел оказывает воздействие две сферы деятельности образовательная и служебная. Образовательная сфера, так как согласно должностному регламенту 


\section{Административное и муниципальное право 8 (104) 2016}

основные права и служебные обязанности курсантов непосредственно связаны с добросовестным освоением образовательной программы и посещением учебных занятий в соответствии с учебным планом. Служебная сфера выражается в том, что курсант в процессе обучения является не только обучающимся, но и сотрудником органов внутренних дел, на которого распространяются положения законодательства, регулирующего вопросы прохождения службы в органах внутренних дел.

Ключевые элементы прохождения курсантами службы в органах внутренних дел можно представить в следующем виде:

1) Зачисление на обучение.

В системе органов внутренних дел Законом о службе установлены четыре основания возникновения правоотношений между гражданином и Российской Федерацией. Наряду с такими основаниями как: назначение на должность, поступление на службу по результатам конкурса, восстановление в должности, самостоятельным основанием возникновения правоотношений между гражданином и Российской Федерацией является зачисление на обучение по очной форме в образовательную организацию высшего образования МВД России. Гражданин, зачисленный на обучение в ведомственную образовательную организацию, считается проходящим службу в полиции. Полиция, структурно входящая в единую централизованную систему органов внутренних дел, соотносится как частное и целое. Каждый сотрудник полиции является сотрудником органов внутренних дел, но не каждый сотрудник органов внутренних дел является сотрудником полиции. Соответственно гражданин, зачисленный на обучение в ведомственную образовательную организацию, считается проходящим службу в органах внутренних дел. В настоящее время к сотрудникам органов внутренних дел предъявляется высокие требования к личным и деловым качествам, на них распространяются ограничения, обязанности и запреты, связанные со службой в органах внутренних дел.

Процедуре зачисления на обучение по очной форме в образовательную организацию высшего образования системы МВД России в обязательном порядке предшествует процедура отбора кандидатов на службу в органы внутренних дел, которая позволяет определить пригодность кандидатов к службе в органах внутренних дел по своим деловым и личным качествам, состоянию здоровья, физической подготовке [4].

Процедура отбора кандидатов, поступающих на обучение и впервые принимаемых на службу в органы внутренних дел, регламентирована приказом МВД России «О некоторых вопросах поступления граждан Российской Федерации на службу в органы внутренних дел Российской Федерации: приказ МВД России» [5].

Прием на обучение в образовательные организации системы МВД России осуществляется на основании ежегодных распоряжений МВД России о комплектовании переменным составом ведомственных образовательных организаций. В соответствии Планами комплектований для каждой организации, органа и подразделения МВД России выделяются места для целевого приема граждан (сотрудников) на обучения. Исходя из закрепления в Плане комплектования для каждого территориального органа МВД России мест для целевого приема, на практике зачастую возникает вопрос о возможности подачи документов гражданином, проживающим на территории субъекта, обслуживаемого другим территориальным органом МВД России, которому не выделены такие места в конкретной ведомственной образовательной организации? Согласно Конституции Российской Федерации право на образование гарантируется независимо от национальности, пола, расы, отношения к религии, происхождения, языка, имущественного, должностного и социального положения, принадлежности к общественным объединениям, убеждений, места жительства и иных обстоятельств [6]. Действующее законодательство, регламентирующее порядок поступления на службу в органы внутренних дел, не содержит норм, определяющих поступление на обучение в образовательную организацию системы МВД России по принципу территориальности. Вместе с тем, в практической деятельности, как правило, гражданин Российской Федерации, изъявивший желание обучаться в ведомственной образовательной организации, обращается в территориальный орган МВД России по месту своего жительства с целью рассмотрения возможности поступления на обучение и последующего прохождения мероприятий, связанных с оформлением на обучение. По общему правилу на службу в органы внутренних дел могут поступать граждане, достигшие возраста 18 лет, и только в случаях зачисления на обучение по очной форме в образовательную организацию высшего образования системы МВД России допускается прием несовершеннолетних граждан с обязательным согласием их законных представителей. Законом о службе для поступающих на очную форму обучения установлен предельный возраст - 25 лет.

В процессе отбора кандидаты на обучение изучаются в ходе медицинского освидетельствования, которое в отличие от граждан, проходящих процесс оформления на службу в органы внутренних дел, проходит в два этапа: предварительное освидетельствование и окончательное. Предварительное медицинское освидетельствование осуществляют 
военно-врачебные комиссии по месту территориального органа МВД России, а окончательное освидетельствование внештатные военно-врачебные комиссии непосредственно в образовательной организации системы МВД России [7]. После успешного прохождения всех мероприятий, связанных с оформлением кандидата на обучение, материалы изучения данных о кандидате направляются в образовательные организации системы МВД России для участия на конкурсной основе во вступительных испытаниях. Только после успешного прохождения гражданином на конкурсной основе вступительных испытаний в образовательной организации системы МВД России возможно издание соответствующего приказа начальника образовательной организации системы МВД России о зачислении гражданина на обучение в должности курсанта, слушателя.

Особенностью является то, что гражданину, поступающему на очную форму обучения в образовательные организации системы МВД России, испытание не устанавливается [2] и личное поручительство не оформляется [8].

Правоотношения на службе в органах внутренних дел в виде зачисления на обучение возникают в результате заключения контракта о прохождении службы в органах внутренних дел. С одной стороны, в соответствии с примерной формой контракта установленной приказом МВД России № 34, контракт о прохождении службы в органах внутренних дел заключают соответствующий начальник образовательной организации системы МВД России и с другой стороны гражданин, успешно выдержавший вступительные испытания [9]. Согласно целевому приему одним из условий контракта является обязанность гражданина после окончания обучения проходить службу в органе внутренних дел, который направил его на обучение. Следует отметить, что в целевом направлении на обучение заинтересованы как абитуриенты, так и территориальные органы МВД России. С одной стороны выпускники, обучавшиеся по целевому направлению, не задумаются о трудоустройстве после окончания обучения, так как процент трудоустройства составляет 100 \%. Территориальные органы МВД России заинтересованы в качественном комплектовании штатных единиц квалифицированными специалистами.

2) Присвоение специального звания обучающимся.

В соответствие с Законом о службе гражданам, поступившим на службу в органы внутренних дел, в установленном порядке присваиваются первые и очередные специальные звания. В соответствии со статьей 43 Закона о службе гражданину, зачисленному на обучение в ведомственную образовательную организацию в должности курсанта, слу- шателя, в установленном порядке присваивается специальное звание рядового состава. Вместе с тем, следует отметить, что согласно штатным расписаниям образовательных организаций системы МВД России для должности «слушатель» предусмотрено специальное звание среднего начальствующего состава «младший лейтенант полиции».

Также для курсантов (слушателей) Законом о службе установлены исключительные порядки присвоения специальных званий. Так, при переводе курсанта на последний курс обучение ему присваивается специальное звание - младший лейтенант полиции и он становится слушателем. Перевод курсантов на следующий курс осуществляется по результатам успешного прохождения промежуточной аттестации. Наличие академической задолженности и не прохождение промежуточной аттестации без уважительных причин являются условиями, препятствующими переводу курсантов на следующий курс, и в данном случае перевод на следующий курс осуществляется условно. В связи с чем, в правоприменительной практике остаточно часто возникает вопрос о возможности и целесообразности присвоения специального звания младшего лейтенанта полиции курсанту, условно переведенному с 4 курса на 5 (последний) курс. Вместе с тем, Законом о службе не предусмотрены основания приостановления присвоения специального звания курсанту, условно переведенному на последний курс обучения. Особенностью также является и то, что согласно приказу МВД России «Об утверждении Порядка присвоения очередных специальных званий, соответствующих должностям среднего и старшего начальствующего состава, до подполковника полиции, подполковника внутренней службы, подполковника юстиции включительно, а также первых и очередных специальных званий, соответствующих должностям рядового состава и младшего начальствующего состава» проект приказа о присвоении специального звания среднего и рядового состава слушателю и курсанту соответственно подготавливается без составления представления о присвоении специального звания [10].

Курсанту (слушателю) окончившему ведомственную образовательную организацию или назначаемому на должность среднего или старшего начальствующего состава после окончания обучения присваивается специальное звание среднего начальствующего состава - лейтенант полиции независимо срока выслуги в предыдущем звании. Норма статьи 43 части 6 Закона о службе требует уточнения формы обучения, так как с формальной стороны сотрудник, проходящий службу в органах внутренних дел, например на должностях младшего начальствующего состава, и окончивший ведомственную образовательную организацию по заоч- 


\section{Административное и муниципальное право 8 (104) 2016}

ной форме, подпадает под действие данной нормы, в соответствии с которой ему должно быть присвоено специальное звание лейтенанта (полиции, внутренней службы или юстиции) независимо от срока пребывания в предыдущем специальном звании. Поэтому часть 6 статьи 43 Закона о службе следует изложить в следующей редакции «Сотруднику органов внутренних дел, окончившему образовательную организацию высшего образования федерального органа исполнительной власти в сфере внутренних дел по очной форме....».

\section{3) Аттестация.}

Курсанты образовательных организаций системы МВД России в процессе прохождения службы и обучения проходят аттестацию. Аттестация применительно для данной категории может выражаться в двух формах: как элемент образовательного процесса и как элемент прохождения службы в органах внутренних дел. Аттестация как элемент образовательного процесса является формой оценки уровня и степени освоения курсантом образовательной программы и представлена 2 видами: промежуточной и государственной итоговой аттестацией.

Аттестация как обязательный элемент прохождения службы в органах внутренних дел служит правовым средством определения степени соответствия сотрудника органов внутренних дел замещаемой им должности на основе оценки его служебной деятельности. Основными нормативными правовыми актами, регламентирующими проведение аттестации в органах внутренних дел, являются Закон о службе и приказ МВД России «О порядке проведения аттестации сотрудников органов внутренних дел Российской Федерации»[11].

Для оценки профессиональной деятельности сотрудника, его деловых и личных качеств, а также его соответствия предъявляемым к сотрудникам органов внутренних дел требованиям, в органе внутренних дел создается соответствующая аттестационная комиссия. Закон о службе для сотрудников органов внутренних дел устанавливает прохождение плановой аттестации и внеочередной. Плановая аттестация, как правило, проводится один раз в четыре года, внеочередная аттестация проводится по основаниям, предусмотренным в статье 33 Закона о службе. Результатами аттестации в зависимости от основания проведения являются рекомендации аттестационной комиссии и решение соответствующего руководителя, вынесенные в соответствии с Законом о службе. Нормы статьи 33 Закона о службе о проведении аттестации в органах внутренних дел не содержат, каких либо ограничений в ее проведении по отношению к курсантам (слушателям) образовательных организаций системы МВД России. Поэтому курсанты при переводе их на вышестоящую должность переменного состава образовательной организации системы МВД России для замещения должностей командира отделения или заместителя командира взвода в обязательном порядке подлежат внеочередной аттестации. Слушатели 5 курсов также подлежат внеочередной аттестации, в связи с переводом на вышестоящую должность в орган внутренних дел, направивший их на обучение, так как должность, на которую будут назначены выпускники, прибывшие по окончании ведомственной образовательной организации, является вышестоящей.

На практике зачастую возникает вопрос о приобретении обучающимися статуса «слушателя». В соответствии с Уставами образовательных организаций МВД России слушателем является лицо, переведенное на последний курс обучения и которому в установленном порядке присвоено специальное звание среднего начальствующего состава. Соответственно для получения статуса «слушателя» необходимо наличие двух условий: перевода на последний курс обучения и присвоения специального звания. Перевод на следующий курс обучения происходит после успешного прохождения промежуточной аттестации, что и является результатом добросовестного освоения образовательной программы. В соответствии с Законом о службе правоотношения на службе в органах внутренних дел возникают в результате зачисления гражданина на обучение в должности курсанта, слушателя, в связи, с чем процедуры назначения на курсанта 4 курса на должность слушателя не требуется. В соответствии с частью 2 статьи 33 Закон о службе курсанты 4 курса проходят плановую аттестацию, которая проводится 1 раз в четыре года.

Четкое определение возникновения административно-правового статуса сотрудника в соответствии с замещаемой должностью исключает случаи неправомерных действиях сотрудников, осуществляющих кадровое обеспечения деятельности органа внутренних дел, и влияет на проведение соответствующих процедур, связанных с его возникновением.

4) Прекращение правоотношений.

Применительно к курсантам (слушателям) образовательных организаций системы МВД России следует говорить о прекращении образовательных отношений и(или) правоотношений, связанных с прохождением службы в органах внутренних дел.

Образовательные отношения с курсантами прекращаются: в связи с получением образования (завершением обучения) или досрочно по основаниям, предусмотренным приказом МВД России [12]. Среди оснований, влияющих на досрочное прекращение образовательных отношений, могут быть: инициатива обучающегося, инициатива непосредственно образовательной организации и обстоятельства независящие от воли сторон. Прекращение образовательных 
отношений между курсантом и образовательной организацией системы МВД России оформляется приказом начальника соответствующей образовательной организации об отчислении из нее.

Под прекращением службы в органах внутренних дел следует понимать установленный нормативно порядок прекращения государственнослужебных правоотношений между сотрудником органов внутренних дел и органом внутренних дел, возникших при поступлении гражданина на службу в органы внутренних дел и в процессе выполнения им служебных обязанностей. Прекращение службы в органах внутренних дел выражается в исключении сотрудника из реестра лиц, замещающих штатную должность в органе внутренних дел.

Прекращение службы в органах внутренних дел возможно только по основаниям, предусмотренным статьей 82 и 82.1 Федерального закона «О службе».

Применительно к курсантам (слушателям) образовательных организаций системы МВД России в некоторых случаях прекращение образовательных отношений наступает одновременно с прекращением правоотношений, связанных с прохождением службы в органах внутренних дел и расторжением контракта о прохождении службы в органах внутренних дел, а в отдельных случаях прекращение образовательных отношений не влечет прекращения правоотношений, связанных со службой. Так в случаях получения образования (завершения обучения), а равно в случаях отчисления не ранее чем с третьего курса по основаниям, не препятствующим дальнейшему прохождению службы в органах внутренних дел, отчисленный из образовательной организации курсант (слушатель) направляется для дальнейшего прохождения службы в орган внутренних дел, направивший его на обучение. При этом увольнение со службы в органах внутренних дел не происходит, правоотношения на службе в органах внутренних дел продолжаются с территориальным органом вну- тренних дел МВД России с изменением служебного статуса сотрудника органов внутренних дел.

Можно говорить и об основаниях прекращения службы в органах внутренних дел, которые фактически не могут быть применены к курсантам (слушателям), например такие как: увольнение по достижению предельного возраста пребывания на службе или по выслуге лет, дающей право на получение пенсии и некоторые другие.

Прекращение срочного контракта, освобождение от замещаемой должности и увольнение курсанта со службы в органах внутренних в период обучения оформляются правовым актом образовательной организации системы МВД России.

Применительно к курсантам Закон о службе также регламентирует: предоставление каникулярных отпусков и отпуска по окончании образовательной организации (ст. 60, ст. 62), принципы и приоритетные направления формирования кадрового состава органов внутренних дел (ст. 75), оплату труда (ст. 66), служебное время и время отдыха (ст. 53-55), гарантии социальной защиты (глава 9), порядок исчисления стажа службы в органах внутренних дел (ст. 38), финансирование службы в органах внутренних дел (ст. 91) и другое.

Таким образом, следует сделать вывод о том, что, во-первых на законодательном уровне должны быть четко закреплены особенности и свойства правоотношений, возникающих в соответствующем виде государственной службы, а во-вторых надлежащим образом должен быть закреплен статус субъектов этих отношений, их права и обязанности, ответственность.

Хорошо организованная система прохождения службы в органах внутренних дел является гарантией органической взаимосвязи целей полицейского ведомства и индивидуальных планов сотрудников, обеспечения ступенчатого профессионального роста личного состава, повышения качества службы в органах внутренних дел и ответственности каждого сотрудника за принимаемые им решения.

\section{Библиография:}

1. О системе государственной службы Российской Федерации: федер. закон Рос. Федерации от 27 мая 2003 г. № $58-$ Ф3 // Российская газета - 2003. - 31 мая.

2. О службе в органах внутренних дел Российской Федерации и внесении изменений в отдельные законодательные акты Российской Федерации: федер. закон Рос. Федерации от 30 ноября 2011 г. № 342-Ф3 // Российская газета - 2011. - 7 декабря.

3. Горин В.Н. Государственная служба в органах внутренних дел: проблемы прохождения. В сборнике: Направления и перспективы развития образования в военных институтах внутренних войск МВД России Сборник научных статей VII Международной научно-практической конференции: В 2 частях. Под общ. ред. С.А. Куценко. 2016. С. 108-111.

4. Об утверждении Порядка и условий приема в федеральные государственные организации, осуществляющие образовательную деятельность и находящиеся в ведении Министерства внутренних дел Российской Федерации: приказ МВД России от 12 марта 2015 г. № 321.// Бюллетень нормативных актов федеральных органов исполнительной власти, № 36. - 2015

5. 0 некоторых вопросах поступления граждан Российской Федерации на службу в органы внутренних дел Российской Федерации: приказ МВД России от 18 июля 2014 г. № 595. // Российская газета, № 223.-2014. 


\section{Административное и муниципальное право 8 (104) • 2016}

6. Конституция Российской Федерации (принята всенародным голосованием 12 декабря 1993 г.) // Собр. законодательства РФ, 4 августа 2014 г. ,№ 31, ст. 4398.

7. Об утверждении Инструкции о порядке проведения военно-врачебной экспертизы и медицинского освидетельствования в органах внутренних дел Российской Федерации и внутренних войсках Министерства внутренних дел Российской Федерации: приказ МВД России от 14 июля 2010 г. № 523.// Российская газета (федеральный выпуск). № 264/1.-2010.

8. Об утверждении Порядка оформления личного поручительства при поступлении на службу в органы внутренних дел Российской Федерации и Категорий должностей, при назначении на которые оформляется личное поручительство: приказ МВД России от 18 мая 2012 г. № 522 // Российская газета, № 156 . - 2012.

9. О примерной форме контракта о прохождении службы в полиции Российской Федерации: приказ МВД России от 19 января 2012 г. № 34. // Российская газета. № 29. - 2012

10. Об утверждении Порядка присвоения очередных специальных званий, соответствующих должностям среднего и старшего начальствующего состава, до подполковника полиции, подполковника внутренней службы, подполковника юстиции включительно, а также первых и очередных специальных званий, соответствующих должностям рядового состава и младшего начальствующего состава: приказ МВД России от 9 января 2013 г. № 3 // Российская газета, № 40.-2013.

11. О порядке проведения аттестации сотрудников органов внутренних дел Российской Федерации: приказ МВД России от 14 марта 2012 г. № 170 // Российская газета, № 94.-2012.

12. О порядке отчисления из федеральных государственных организаций, осуществляющих образовательную деятельность и находящихся в ведении МВД России, порядке восстановления в таких организациях и порядке перевода обучающихся по основным профессиональным образовательным программам из одной федеральной государственной организации, осуществляющей образовательную деятельность и находящейся в ведении МВД России, в другую такую организацию: приказ МВД России от 7 июля 2014 г. № 568 г. // Российская газета, № 196 - 2014.

13. Дресвянникова Е.А. Некоторые вопросы качественного отбора кандидатов на службу в органы внутренних дел // Полицейская деятельность. - 2014. - 5. - С. 448 - 451. DOI: 10.7256/2222-1964.2014.5.13043.

\section{References (transliterated):}

1. O sisteme gosudarstvennoi sluzhby Rossiiskoi Federatsii: feder. zakon Ros. Federatsii ot 27 maya 2003 g. № 58-FZ // Rossiiskaya gazeta - 2003. - 31 maya.

2. O sluzhbe v organakh vnutrennikh del Rossiiskoi Federatsii i vnesenii izmenenii v otdel'nye zakonodatel'nye akty Rossiiskoi Federatsii: feder. zakon Ros. Federatsii ot 30 noyabrya 2011 g. № 342-FZ // Rossiiskaya gazeta - 2011. - 7 dekabrya.

3. Gorin V.N. Gosudarstvennaya sluzhba v organakh vnutrennikh del: problemy prokhozhdeniya. V sbornike: Napravleniya i perspektivy razvitiya obrazovaniya v voennykh institutakh vnutrennikh voisk MVD Rossii Sbornik nauchnykh statei VII Mezhdunarodnoi nauchno-prakticheskoi konferentsii: V 2 chastyakh. Pod obshch. red. S.A. Kutsenko. 2016. S. 108-111.

4. Obutverzhdenii Poryadka iuslovii priemav federal'nye gosudarstvennye organizatsii, osushchestvlyayushchie obrazovatel'nuyu deyatel'nost' i nakhodyashchiesya v vedenii Ministerstva vnutrennikh del Rossiiskoi Federatsii: prikaz MVD Rossii ot 12 marta 2015 g. № 321.// Byulleten' normativnykh aktov federal'nykh organov ispolnitel'noi vlasti, № 36. - 2015

5. O nekotorykh voprosakh postupleniya grazhdan Rossiiskoi Federatsii na sluzhbu v organy vnutrennikh del Rossiiskoi Federatsii: prikaz MVD Rossii ot 18 iyulya 2014 g. № 595. // Rossiiskaya gazeta, № 223.-2014.

6. Konstitutsiya Rossiiskoi Federatsii (prinyata vsenarodnym golosovaniem 12 dekabrya 1993 g.) // Sobr. zakonodatel'stva RF, 4 avgusta 2014 g. ,№ 31, st. 4398.

7. Ob utverzhdenii Instruktsii o poryadke provedeniya voenno-vrachebnoi ekspertizy i meditsinskogo osvidetel'stvovaniya v organakh vnutrennikh del Rossiiskoi Federatsii i vnutrennikh voiskakh Ministerstva vnutrennikh del Rossiiskoi Federatsii: prikaz MVD Rossii ot 14 iyulya 2010 g. № 523.// Rossiiskaya gazeta (federal'nyi vypusk). № 264/1.-2010.

8. Ob utverzhdenii Poryadka oformleniya lichnogo poruchitel'stva pri postuplenii na sluzhbu v organy vnutrennikh del Rossiiskoi Federatsii i Kategorii dolzhnostei, pri naznachenii na kotorye oformlyaetsya lichnoe poruchitel'stvo: prikaz MVD Rossii ot 18 maya 2012 g. № 522 // Rossiiskaya gazeta, № 156 . - 2012.

9. O primernoi forme kontrakta o prokhozhdenii sluzhby v politsii Rossiiskoi Federatsii: prikaz MVD Rossii ot 19 yanvarya 2012 g. № 34. // Rossiiskaya gazeta. № 29. - 2012

10. Ob utverzhdenii Poryadka prisvoeniya ocherednykh spetsial'nykh zvanii, sootvetstvuyushchikh dolzhnostyam srednego i starshego nachal'stvuyushchego sostava, do podpolkovnika politsii, podpolkovnika vnutrennei sluzhby, podpolkovnika yustitsii vklyuchitel'no, a takzhe pervykh i ocherednykh spetsial'nykh zvanii, sootvetstvuyushchikh dolzhnostyam ryadovogo sostava i mladshego nachal'stvuyushchego sostava: prikaz MVD Rossii ot 9 yanvarya 2013 g. № 3 // Rossiiskaya gazeta, № 40.-2013.

11. O poryadke provedeniya attestatsii sotrudnikov organov vnutrennikh del Rossiiskoi Federatsii: prikaz MVD Rossii ot 14 marta 2012 g. № 170 // Rossiiskaya gazeta, № 94.-2012.

12. o poryadke otchisleniya iz federal'nykh gosudarstvennykh organizatsii, osushchestvlyayushchikh obrazovatel'nuyu deyatel'nost' i nakhodyashchikhsya v vedenii MVD Rossii, poryadke vosstanovleniya $v$ takikh organizatsiyakh i poryadke perevoda obuchayushchikhsya po osnovnym professional'nym obrazovatel'nym programmam iz odnoi federal'noi gosudarstvennoi organizatsii, osushchestvlyayushchei obrazovatel'nuyu deyatel'nost' i nakhodyashcheisya v vedenii MVD Rossii, v druguyu takuyu organizatsiyu: prikaz MVD Rossii ot 7 iyulya 2014 g. № 568 g. // Rossiiskaya gazeta, № 196 - 2014.

13. Dresvyannikova E.A. Nekotorye voprosy kachestvennogo otbora kandidatov na sluzhbu v organy vnutrennikh del // Politseiskaya deyatel'nost'. - 2014. - 5. - C. 448 - 451. DOI: 10.7256/2222-1964.2014.5.13043. 